Mergen, F. (2018). Beyin araştırmaları ışı̆ında yabancı dil sınıflarında anadili kullanımı. Ana Dili Eğitimi Dergisi, $6(3), 553-568$.

$\begin{gathered}\text { Ana Dili Eğitimi Dergisi } \\ \text { Journal of Mother Tongue Education } \\ \text { www.anadiliegitimi.com }\end{gathered}$
Geliş/Received: 28.03 .2018 Kabul/Accepted:07.06.2018

\title{
Beyin Araştırmaları Işığında Yabancı Dil Sınıflarında Anadili Kullanımı
}

\author{
Filiz MERGEN*
}

\begin{abstract}
Öz
Anadili edinimi hızlı ve zahmetsiz ilerleyen bir süreç olmasına rağmen, sonradan öğrenilen dil, birçok birey için birtakım zorluklar teşkil etmektedir. Özellikle, geç yaşta öğrenilen dilde iletişim kurabilmek bireyler için son derece uzun ve yorucu olabilmektedir. Sınıf ortamında bu zorlukları ortadan kaldırmayı amaçlayan görüşler, özellikle teknoloji ve bilgi paylaşımının ilerlemesiyle önemli ölçüde başarılı olmuşlardır. Ancak, bu süreçte anadilinin rolü tartışma konusu olmuştur. Bu makalede, öğrencilere öğrendikleri yabancı dilde iletişim kurabilmelerini sağlamak için sadece hedef dilin kullanılmasını öngören görüşlerin dil öğrenimi üzerindeki etkilerinin beyin ve dil açııından değerlendirilmesi yapılmıştır. Duygusal (afektif), bilişsel ve psikodilbilimsel ve beyindilbilimsel çalışmalardan elde edilen verilere dayanarak, anadili kullanımının dil eğitiminin her aşamasında tamamen kıııtlanması olası görülmemekte ve dil öğrenme başarısını da olumsuz yönde etkileyeceği düşünülmektedir.
\end{abstract}

Anahtar Kelimeler: Yabancı dil eğitimi, anadili, duygular, psikodilbilim, beyindilbilim

\section{An Investigation of L1 Use in Foreign Language Classrooms: Evidence from Brain Research}

\begin{abstract}
First language acquisition (L1) proceeds quickly and effortlessly. The acquisition of a second language (L2) - later in life, however, poses some difficulties. Age and context of acquisition determine the extent of success of ultimate attainment in the later-learned language. Extensive research into what lies behind this difficulty has led to many views aiming to facilitate the learning process. One view, the use of mother tongue has always been a matter of controversy during the learning process. There has been a range of views, both for and against, particularly in the context of teaching a foreign language in formal education. This article assesses the consequences of the views that favor target-language-only approach in teaching in the light of brain research. It puts forward an argument based on the data obtained from affective, cognitive and psycholinguistic/neurolinguistic literature that banishing L1 from the classroom is not only impossible for practical reasons, but also acts as a deterrent to successful language learning.
\end{abstract}

Keywords: Foreign language teaching, Mother tongue, Emotions, Psycholinguistics, Neurolinguistics

\section{Giriş}

Günümüzde yabancı dil öğrenmenin zorunluluğu tartışılmazdır. Ancak, anadili ediniminden sonra ikinci bir dili öğrenmek, özellikle de çocukluk döneminden sonra, çoğu birey için zor ilerleyen bir süreçtir. Birçok etkenin rol aldığı yabancı dil öğrenimi bu alanda çalışan araştırmacılar tarafından

*Dr., İzmir Ekonomi Üniversitesi, Meslek Yüksek Okulu, Uygulamalı İngilizce ve Çevirmenlik Programı. İzmir 
çeşitli boyutlarıyla ele alınmış, bu zorlu süreci dil öğrenen bireyler adına daha kolay hale getirme yolunda birçok görüş ortaya atılmıştır. Her bir yeni öğretim metodunun bir öncekinin eksiklerini kapatacağı varsayılmış, öğrencilere bu yöntemlerle dil öğretimi hedeflenmiştir. Bunlardan en sonuncusu olan ve 1980 'lerde başlayan İletişimsel Dil Öğretimi hala güncelliğini korumaktadır. Bu ve bundan önce yabancı dilde iletişime öncelik veren yaklaşımların hedefi, bireyleri öğrendikleri yabancı dili bir iletişim aracı olarak kullanabilmelerini sağlayacak şekilde eğitmektir. Bunun gereği olarak, dil sınıflarında hedef dil, eğitim ve iletişim aracı olarak kullanılmaktadır. Bu süreçte anadilin kullanılması söz konusu değildir, zira bu durumda dil öğrenen bireylerin öğrendikleri yabancı dilde yeterince dil girdisine maruz kalmaları engellenmiş olacaktır. Bu görüşü destekleyen eğitimciler ve eğitim bilimciler anadilin kullanılmasını adeta "yasaklamış", sınıf içinde her tür eğitimin hedef dilde gerçekleşmesi gerektiğini vurgulamışlardır. Yabancı bir dili sınıf ortamında öğrenen öğrencilerin mümkün olduğu kadar fazla dil girdisine maruz kalmalarının, o dili öğrenmede ve o dili kullanarak iletişim kurmada onlara önemli bir katkı sağladığı tartışılmazdır. Ancak, bunu sağlamak için hem dil öğretmeninin hem de öğrencilerin anadili kullanımının kısıtlanması, özellikle de, ülkemizde adeta yasaklanması çok gerçekçi bir yaklaşım olarak görünmemektedir. Littlewood ve Yu (2011), alan yazında, yabancı dil sınıflarında anadili kullanımını destekleyen ve karşı çıkan görüşleri ele aldıkları makalelerinde, anadili kullanımı kısıtlanmasının hedef dil kullanımının önüne geçebileceği endişesinden kaynaklandığııı aktarmışlardır. Yazarlar, aynı zamanda birçok çalışmanın, öğrenci ve öğretmen arasında sosyal ve duygusal etkileşim kurma, karmaşık dil yapılarının açıklanması ve sınıfta disiplinin sağlanması gibi durumlarda anadili kullanımının kaçınılmaz olduğu görüşünün hakim olduğunu bildirmişlerdir. Özellikle duygusal açıdan, anadilinin öğrencilerde bir güven duygusu oluşturduğunu vurgulamışlardır. 1990'lı yıllardan beri hızla ilerleyen beyin araştırmalarından elde edilen veriler ise, yabancı dil sınıflarında anadili kullanımıyla ilgili kısıtlamaların tekrar gözden geçirilmesi gerektiğini ortaya çıkarmıştır. Bu makalede, yabancı dil sınıfında hem öğretmenlerin hem de öğrencilerin anadili kullanımının kaçınılmazlığı beyin dilbilimi alanında elde edilen gelişmeler ışığında tartışılacak, duygusal, bilişsel ve psikodilbilimsel / beyindilbilimsel açıdan incelenecektir.

\section{Duygusallık}

Sağ|ıklı olarak dünyaya gelen her bebek, ilk dört yılın sonunda içinde büyüdüğü toplumun konuştuğu dili anadili olarak edinir. Aslında yeni doğmuş bir bebeğin, çevresinde konuşulan dillerin tümünü eş zamanlı olarak öğrenme potansiyeli vardır (Kuhl, 2004; 2010), ancak tek dilin konuşulduğu bir ortamda büyüyen bir bebek tekdilli, birden fazla dilin konuşulduğu bir ortamda büyüyen bir bebek ise çokdilli olur. Dil edinimi, herkesin bildiği gibi sorunsuz ilerleyen bir süreçtir. Tüm bebekler benzer aşamalardan geçerek anadillerini konuşmaya başlarlar. Beynin tüm sistemlerinin eş zamanlı olgunlaşmaya başladığı erken dönemde gerçekleşen dil edinimi, kuşkusuz anadilini o dilin 


\section{Beyin Araştırmaları Işığında Yabancı Dil Sınıflarında Anadili Kullanımı}

konuşucuları için ikinci dilden farklı bir konuma getirmektedir. Aslında bu farklılık, gerçek anlamda bir "ayrıcalık" olarak görülebilir, zira özellikle duygu sistemiyle eş zamanlı gelişen dil sisteminin anadili konuşucuları için farklı bir yeri vardır. Evrim boyunca insanoğlunun hayatta kalma çabalarıyla şekillenen duygu sistemi, beyinde bebeklik döneminde olgunlaşmaktadır (Lewis, 2004: 276). Bebeğin büyüdüğü ortamdaki duygusal deneyimleriyle olgunlaşan bu sistem, içinde bulunduğu toplumun diliyle anlam kazanmaktadır. Daha sonra bu deneyimlerin aktarılması, ifade edilmesi ya da benzer deneyimlerin yaşanması durumunda anadili önemli bir rol oynamaktadır. Pavlenko (2004) çocukluk döneminde duygusal deneyimlerle şekillenen anadilinin daha zengin bir anlam ağında temsil edildiğini bildirmiştir. Bu süreçten sonra ikinci bir dil öğrenilmesi durumunda, duygu sistemi ve dil sistemi iki ayrı olgu olarak karşımıza çıkmaktadır. Bir başka deyişle, bebeklik ve erken çocuklukta duygusal deneyimlerle desteklenen dil sistemi, ikinci bir dilin edinilmesine tam olarak destek vermemektedir. Bu durum, en azından, alan yazında "temel duygular" olarak adlandırılan duyguların (Ekman, 1992) deneyimi ve aktarımı için geçerlidir. Alan yazında bu görüşü destekleyen birçok çalışma mevcuttur. Hem deneysel çalışmalar, hem de ikinci dilini anadilinden sonra öğrenen bireylerin duygusal deneyimleriyle ilgili verdikleri bilgilere dayanarak, duyguların ifade edilmesi ve algısında anadilinin tercih sebebi olduğunu görülmektedir. Örneğin, duygusal durumlarda bildikleri dillerden hangisini kullandıkları sorulduğunda, ikidilli bireyler anadillerini tercih ettiklerini bildirmişlerdir (Pavlenko, 2004). ỉki veya daha fazla dili anadillerinden sonra öğrenen bireylerin yer aldığı bir çalışmada Dewaele ve Nakano (2013), katılımcıların bildikleri dillerdeki duygusallık algısını incelemişlerdir. Katılımcıların ilk öğrendikleri dili (anadili), bildikleri diğer dil ve dillerden daha duygusal buldukları ortaya çıkmıştır. Katılımcılar, kendilerini ifade ederken anadillerini "daha gerçekçi, ciddi ve mantıklı" bulduklarını dile getirmişlerdir.

Sınıf ortamında yabancı dil eğitimiyle ilgili yapılan çalışmalar da bu fikri desteklemektedir. Pavlenko ve Driagina (2007) anadili İngilizce olan ve Rusça'yı formal eğitimle öğrenen ve dil yeterliliği yüksek olan bireylerin izledikleri bir filmi, öğrendikleri yabancı dilde anlatmalarını istemişler ve sonuçları Rusça'nın anadili konuşucuları ile karşılaştırmışlardır. Sonuçlar, Rusça'yı yabancı dil olarak öğrenen katılımcıların, diğer gruba göre daha uzun anlatımlar ürettiğini, ancak duygu dili kullanımının yetersiz olduğunu ortaya çıkarmıştır. Yazarlar anlatımların uzunluğunu, öğrencilerin yabancı dildeki duygu yükü eksikliğini fazla tekrar ve dolaylı anlatımla kapatma çabası olarak değerlendirmişlerdir. Dewaele (2005) yabancı dil sınıflarındaki duygu içerikli dil kullanımının eksikliğine dikkat çekmektedir. Öğrencilere yabancı dildeki sözcüklerin duygu yükünü iletmenin bir yere kadar mümkün olduğunu söylemekle birlikte, bunun etik olarak önemli sonuçlar doğurabileceğine dikkat çekmektedir. Dewaele ve Pavlenko (2002) ise, duygu içerikli dil üretimi söz konusu olduğunda, öğrencilerin biçimsözdizimsel olarak daha fazla hatalı cümleler ürettiklerini aktarmaktadır. Segalowitz vd. (2008) ise anadili İngilizce 
olan ve Fransızca'yı yabancı dil olarak öğrenen katılımcılarla yaptıkları çalışmada, katılımcılardan her iki dilde ekranda gördükleri sözcüklerin olumlu ya da olumsuz olup olmadığına karar vermelerini istemişlerdir. Bu görev sırasında katılımcıların cevap verme süreleri kaydedilmiştir. Elde edilen bulgular, anadilden sonra öğrenilen dildeki duygu içeriğinin değerlendirilmesinin anadildekinden daha yavaş gerçekleştiğini, sözcük tanıma hızının sözcüklerin duygu içeriklerini tanıma hızıyla aynı olmadığını ortaya çıkarmıştır. Benzer şekilde, Opitz ve Degner (2012) anadilden sonra öğrenilen dilde duygu içerikli sözcükleri tanıma görevini kullanarak, katılımcıların beyin aktivitelerini kaydetmişlerdir. Olaya İlişkin Potansiyeller (ERP) yöntemiyle kaydedilen verilerin analizi, sonradan öğrenilen dildeki duygu sözcüklerinin daha geç algılandı̆ıını ortaya çıkarmıştır. Dewaele ve Pavlenko (2002) ise, aradildeki duygu sözcüklerinin kullanımını inceledikleri çalışmalarında İngilizce'yi yabancı dil olarak öğrenen bir grupla, geç öğrenen ancak A.B.D.'de yaşayan bireyleri karşılaştırmışlardır. Bireylerin içe dönük ya da dışa dönük bir kişilik yapısına sahip olmaları ve sosyo-kültürel yeterlilik düzeylerinin duygu dili kullanmalarında etkili olduğunu bildirmişlerdir.

Alanyazında yapılan bu çalışmalar göz önünde bulundurulduğunda, yabancı dil sınıflarında geçerli olan ve iletişimin sadece hedef dilde yapılması gerekliliği düşüncesi, ilk olarak iletişimin vazgeçilmez bir parçası olan duygu içerikli dilin varlığını göz ardı etmiş gibi görünmektedir. Yabancı dil eğitiminde duygu olgusunu ele alan çalışmalar da, dil öğrenen bireylerin dile olan tutumu, motivasyon düzeyi ve olumlu bir öğrenme ortamının yaratılmasıyla sınırlandııılmış, öğrenilen dilde duygu içerikli dil üretimi ve algısı ele alınmamıştır (Krashen, 1982; Dörnyei, 1994; Ehrman, Leaver ve Oxford, 2003; Lopez ve Aguilar, 2013). Bu noktada, duygularını ifade etmek isteyen bir dil öğrencisi için, sadece hedef dilin kullanılmasını zorunlu kılan bir ortamın dil öğrenme sürecini aksatması kaçınılmazdır. Böyle bir ortamda dilbilgisi ve sözcük bilgisi açısından yeterli olmayan bir öğrencinin duygularını ifade etmekte zorlanması bir öğrencinin motivasyonu olumsuz yönde etkileyecek, buna bağlı olarak da ilerlemesini yavaşlatacaktır. Benzer şekilde, öğretmenin (eğer o yabancı dilin anadili konuşucusu ise) duygularını paylaştığı bir durumda, öğrencilerin bunu tam olarak anlayamaması iletişim adına olumsuz bir durum oluşturacaktır. Aynı durum öğrettiği dilin anadili konuşucusu olmayan bir dil öğretmenini de etkileyecektir. Örneğin, öğrencileri ödüllendirmek, cesaret vermek, hatalarını kırıcı olmadan hatırlatmak, ya da öğrencilerin özel problemleriyle ilgili onlara destek vermek için anadilini tercih edebilir. Bu tercih, dildeki yeterlilik düzeyine göre değil, o dilin birey üzerinde yarattığı etkiye göre belirlenmektedir. Tahmin edilenin aksine, anadilinden sonra öğrenilen dilde duyguların ifadesi ve algısı, o dildeki yeterlilik düzeyine bağlı değildir. Pavlenko (2004), yeterlik düzeyi yüksek bireylerin de duyguların ifade ve algısında anadilini tercih ettikleri bildirmiştir. İkinci dillerinde yeterlilik düzeyi yüksek olan birçok ikidilli birey de anadillerini duygusal açıdan daha etkili bulduklarını bildirmişlerdir (Pavlenko, 2004; Dewaele, 2004a; 2004b; 2008; Dewaele ve Nakano, 
2013). Deneysel çalışmalar da bu fikri desteklemektedir (Anooshian ve Hertel, 1994; Harris Ayçiçeği ve Gleason, 2003; Harris, 2004; Caldwell-Harris ve Ayçiçeği-Dinn, 2009). Örneğin, Harris Ayçiçeği ve Gleason (2003), A.B.D.'de yaşayan ve yeterlilik düzeyi yüksek olan ikidilli katılımcıların yer aldığı çalışmalarında, özellikle çocukluk döneminde öğrenilen anadiline ait duygu ifadelerinin katılımcılar üzerinde daha etkili olduğunu bildirmişlerdir.

Dil sınıflarında iletişimin sadece hedef dille yapılması zorunluğunu savunan görüşlerin, duygu içerikli dil kullanımının yanı sıra, öğrencilerin stres ve endişeyle baş edebilme becerilerinin de dil öğrenimi üzerindeki etkisini göz önünde bulundurmaları gerekmektedir. Örneğin, endişeyle baş edebilme ve belirsizliğe olan tolerans öğrencilerin başarısını etkileyebilecek bir faktördür. Bu görüşü destekleyen bir çalışmada öğrencilerin sınıfta yaşadıkları endişe düzeyi ile belirsizlik ortamında gösterdikleri tolerans düzeyi arasındaki ilişki ele alınmıştır (Dewaele ve Ip, 2013). Çalışmadan elde edilen veriler, sözü edilen bu iki durum arasında negatif bir korelasyon olduğuna işaret etmektedir. Dil yeterliliğinin artmasıyla toleransın artıp, endişe oranının düşmesi de dikkat çekicidir. Yabancı dil sınıflarında öğrencileri bireysel olarak değil, bir grup olarak ele alan bir yaklaşım, özellikle dil eğitiminin başlangıç aşamalarında hedef dilde iletişim kurma zorunluluğu koyarak öğrencilerin başarısı olumsuz yönde etkileyecektir.

Sınıf disiplinini sağlamak için de bazı durumlarda anadilinin kullanılması kaçınılmazdır. Daha önceki bölümlerde bahsedilen deneysel araştırmaların sonuçlarına dayanarak, anadilinin insanın duygu sistemini doğrudan harekete geçirmesiyle sonradan öğrenilen dile göre ayrıcalıklı bir konumda olduğu görülmektedir. Özellikle kalabalık sınıflarda sessizliğin sağlanması, öğrencilerin bir konuya dikkat çekilmesi ya da öğrenciye geribildirim verilmesi gibi durumlarda anadili kullanılması hem dersi veren öğretmenin işini büyük ölçüde kolaylaştıracak, hem de öğrenciye fayda sağlayacaktır. Ayrıca, geribildirim vermek, öğretmenler için öğrenciyle birebir iletişim kurmak, öğrenciyi motive etmek ya da disiplin sorunlarını çözmek için önemli birer fırsattır. Böyle bir fırsatı anadilinde gerçekleştirmek kaçınılması gereken bir durum değil, öğretmenin öğrencileri yararına kullanabileceği bir ayrıcalık olarak görülmelidir. Sınıfta anadili kullanımının disiplin açısından pragmatik sonuçlarına dikkat çeken Littlewood ve Yu (2011), anadili kullanımının, hem öğretmene zaman kazandırarak işini kolaylaştıracağını, hem de isteksiz öğrencilerin dikkatini çekerek onları da öğrenme ortamına dahil edebileceğini bildirmişlerdir.

\section{Bilişsel Kaynaklar}

Yabancı dil sınıfında her tür iletişimin anadili yerine sadece hedef dille yapılması gerekliliği beynin bilişsel kaynaklarını etkili kullanması açıdan da tekrar düşünülmesi gereken bir durumdur. Zira, yabancı dil öğrenen bireylerin anadillerinden farklı bir yeterlilik düzeyinde olan bir dilde, anadili 
etkinliğinde konuşabilmelerini beklemek imkansızdır. Alanyazında bu fikri destekleyen çalışmalardan edinilen verilere göre, anadilinden sonra öğrenilen dilde beyinde dil işlemlemede farklı stratejiler kullanmaktadır (Guo vd., 2009). Daha önceden belirtildiği gibi, beyinde birçok işlevi yerine getiren sistemlerin eş zamanlı olgunlaştığı erken çocukluk döneminde, dil sistemi diğer işlevlerle koordineli çalışacak şekilde yerleşir ve otomatik olarak işlemlenmeye başlar (Dehaene-Lambertz vd., 2006). Anadilinden sonra öğrenilen dil ise farklı sistemler tarafından desteklenen ve kontrollü işleyen bir süreçtir. Beyin görüntülerinin alındığı çalışmalarda bunu destekleyen önemli bulgular edinilmiştir (Hasegawa vd., 2002; Indefrey, 2006; Suh vd., 2007). Özellikle dikkat ve bellek sistemlerinin anadilinden sonra öğrenilen dilde, ve özellikle başlangıç aşamalarında, farklı şekilde işlemlendiği ortaya çıkmıştır (UIIman, 2001). Elde edilen veriler katılımcıların anadillerinden sonra öğrendikleri bir dilde verilen faaliyetleri yerine getirirken, beyinlerinde anadillerinde aktive olan alanlardan daha çok beyin alanının aktif olduğunu göstermektedir (Perani ve Abutalebi, 2005; Abutalebi, 2008). Özellikle, dikkat gibi yönetici işlevlerden sorumlu olan frontal lobun (beynin ön bölgesi) aktivasyonu dikkat çekicidir (Wartenburger vd. 2003; Sakai, 2005). Bu bulgular, anadilinden sonra öğrenilen bir dilde yapılan dil faaliyetlerinin beyin için bilişsel bir yük getirdiği şeklinde yorumlanmaktadır. Bu durum, dil sınıfında anadilinden farklı bir dilde iletişim kurmaya çalışan öğrencilerin, dikkat süreçlerini kontrol eden bilişsel kaynakları daha fazla kullandıkları anlamına gelir. Dikkatin ve buna bağlı olarak konsantrasyonun azalması, öğrencilerin hedef dili algılamaları ve ifade etmelerinde sorun yaşamalarına sebep olabilir. Dikkat sistemi üzerindeki yükün (yorgunluk, stres ve konsantrasyon eksikliği) karmaşık dil yapılarının işlemlenmesinde anadili konuşucularını bile zorladığını ortaya çıkaran çalışmalar mevcuttur (McDonald, 2006). Yeni öğrendiği bir dilde kendini ifade etmeye çalışan bir öğrencinin yaşadığı stres göz önünde bulundurulduğunda, tüm iletişimin aralıksız olarak hedef dilde yürütülmeye çalışılması, özellikle düşük seviyede dil bilgisine sahip öğrencilerin performansını etkileyecek önemli bir faktördür.

Ellis (2005) dil eğitiminde göz önünde bulundurulması gereken prensipler arasında, örtük (işlemsel) dil bilgisinin önemini vurgulamış, dil eğitimi müfredatında öncelikli ve ağırlıklı olarak yer alması gerektiğini bildirmiştir. Buna göre, örtük bilginin öğrenilen dildeki iletişim becerileri ve akıcılı̆ı̆ kuvvetlendirdiği düşünülmektedir. Bu görüşün, bilişsel açıdan tekrar düşünülmesi gerekmektedir. Beyinbilimi çalışmalarından edinilen bilgiler, sınıf ortamında bildirimsel olarak öğrenilen bilginin, tekrarlandıkça örtük bilgiye dönüşemeyeceğini göstermektedir. Bunun sebebi, her iki bilgi türü arasında nitel farklılıklar olması ve farklı beyin alanlarının kontrolünde gerçekleşmeleridir. Ullman'ın (2001; 2004; 2015: 143) Bildirimsel-işlemsel Bellek modeline göre, bir dile ait sözcüksel bilgi, zihinsel sözlükçede yerleşmiştir ve bildirimsel bellekte saklanan bilgiyi kontrol eden beyin alanlarının sorumluluğundadır. Bu alanlar, evrim sürecinde sonradan gelişmiş neokortikal alanlardır. Bir dile ait 


\section{Beyin Araştırmaları Işığında Yabancı Dil Sınıflarında Anadili Kullanımı}

dilbilgisi ise işlemsel bellekte yerleşmiştir ve beyinde bazal ganglia, serebellum gibi otomatik işlemleme yapan alanlar tarafından desteklenmektedir. Burada dikkat çekilmesi gereken bir nokta, işlemsel belleği destekleyen beyin alanlarının olgunlaşmasını çocukluk döneminde tamamlayan yapılar olmasıdır (Paradis, 2004: 9). Ullman’a göre (2015) sözü edilen bu farklar dışında, bildirimsel ve işlemsel bellek arasında dil öğrenimini yakından ilgilendiren iki önemli fark daha vardır. Bunlardan ilki, öğrenmenin bildirimsel bellekte hızlı, işlemsel bellekte ise yavaş ve zaman içinde tekrarlanmak suretiyle gerçekleşmesidir. İki bellek sistemi arasındaki diğer bir fark ise, öğrenmenin çocukluk döneminde daha çok işlemsel belleğe dayalı olması, yaş ilerledikçe bildirimsel bellek kontrolünün artmasıdır. Bir başka deyişle, Bildirimsel-i̇şlemsel Bellek Modeline göre, yüklü bir müfredatın kısıtlı bir sürede işlendiği sınıf ortamında örtük bilgi ediniminin gerçekleşmesi, özellikle de çocukluk döneminden sonra gerçekleşmesi mümkün görünmemektedir.

Anadili edinimi ve ikinci dilin öğrenim süreçlerinde beynin bilişsel açıdan farklı olduğu bilinmektedir. Kuhl (2010) anadili ediniminden sonra öğrenilen dilde bireylerin bilişsel olgunluk açısından anadili edinim sürecindeki çocuklardan daha üstün durumda olduklarını bildirmiştir. Ancak, bireylerin ikinci dille tanıştıkları ortamdaki dil girdisi (dilbilgisi yapıları, sözcük çeşitliliği), onların dili anlamalarını sağlayacak şekilde kolaylaştırılmakta ve sadeleştirilmektedir. Bir başka deyişle, öğrendikleri dil yapıları sahip oldukları biliş düzeyi ile bir tezatlık göstermektedir. Bunun yanı sıra, ders sırasında anadilini kullanmaktan kaçınmak isteyen bir yabancı dil öğretmeni hedef dildeki soyut kavramların ya da anlaşılamayacağı düşünülen zorluktaki dil yapılarını, mümkün olan en basit şekliyle anlatmak zorunda kalabilir. Bu da, doğal olmayan bir ortamın oluşmasına sebep olur. Bu durumu Krashen (1982: 31-32) sınıfta kullanılan yabancı dil girdisinin, o dilin anadili konuşucularından farklı olduğunu şeklinde tanımlamış ve söz edilen bu farkın her zaman, öğrencilerin dildeki yeterliliklerinin artmasıyla doğru orantılı olmadığına dikkat çekmiştir. Macaro (2005) ise, öğretmenlerin anadilini kullanmaktan kaçınmak adına başvurdukları bu yöntemi "çocuksu görevler" olarak adlandırmış, öğrencilerin kendilerini çocuk gibi hissetmelerine sebep olacağını savunmuştur. Bu sebeple, anadili kullanmaktan kaçınmak için, yabancı dildeki karmaşık yapıların dil öğretmenleri tarafından kolaylaştırılması, bunların tekrarlanarak başka ifadelerle söylenmesi gerçekçi bir yaklaşım değildir. Bu yaklaşımın, öğrenciler, özellikle de yetişkin öğrenciler için motivasyonu olumsuz yönde etkilemesi söz konusu olacaktır. Bir başka deyişle, doğalıktan uzak bir dil kullanmaktansa, zor yapıların anlatılması, öğrencilerin ihtiyaç duyduğu önemli ipuçlarının verilmesinde anadili kullanımında bir sakınca görülmemelidir. Bu tutum, öğrencileri hedef dilden uzaklaştırmayacak, tam tersine ilerlemelerini sağlayacak bir ortam sağlayacaktır.

Daha önce de belirtildiği üzere, içe dönük ya da dışa dönük bir kişiliğe sahip olmak dildeki duygu ifadelerinin kullanılmasında önemli bir etkendir (Dewaele ve Pavlenko, 2002). Bireysel 
farklııkların dil öğrenimi üzerindeki etkisi ile ilgili yapılan çalışmalar, bu bireylerin bilişsel olarak da birbirlerinden farklı olduğunu göstermiştir. Örneğin, dışa dönük kişilik yapısına sahip bireylerin bellek kapasitelerinin içe dönük bireylerinkinden farkı olduğu bilinmektedir. Bu iki grup birey arasındaki bilişsel farklılıkların dil eğitiminde göz önünde bulundurulması gerekmektedir. Dewaele ve Furnham (1999), dışa dönük kişilik özelliğine sahip bireylerin, kısa süreli belleğe dayalı sözel testlerde içe dönük bireylere göre daha başarılı olduklarını, buna karşıık, uzun süreli bellek açısından içe dönük bireylerin gerisinde kaldıklarını bildirmişlerdir. Dil algısı ve üretiminde hem kısa süreli hem de uzun süreli belleğin önemli rol oynadığı fikrinden hareketle (Ullman, 2001; 2004), farklı kişilik yapısına sahip öğrencilerin, hedef dili aynı hı ve etkinlikte kullanmaları beklenmemelidir. Dewaele ve Furnham (2000), kişilik yapısının dil üretimi ile ilişkisini inceledikleri çalışmalarında, katılımcıların öğrendikleri yabancı dilde (Fransızca) farklı konular üzerinde konuşmalarını istemişlerdir. Hem stresli hem de rahat ortamlarda gerçekleştirilen çalışmada, katılımcıların dil üretimini oranı, tarzları, akııılıkları, kullandıkları sözcüklerin çeşitliliği, doğruluk oranları ve tümce uzunlukları arasında sahip oldukları kişilik yapılarına göre bazı farklar olduğu ortaya çıkmıştır. Elde edilen veriler, özellikle stres altındaki dışa dönük katılımcıların, içe dönük katıımcılardan daha başarılı olduklarını göstermiştir. Kısa süreli bellek becerileri, dışa dönük katılımcılara yukarıda sözü edilen ölçütler açısından avantaj sağlamıştır. Sonuç olarak, bilişsel kaynakları kullanma açısından farklı kişilik yapıları arasındaki farklııklar göz önünde bulundurulduğunda, içe dönük ve dışa dönük kişilik yapısına sahip olan öğrencilerin dil üretiminde aynı derecede başarılı olmaları beklenmemelidir. Böyle bir ortamda iki gruptaki öğrencilerin sınıfta anadili yerine yabancı dilde kendilerini ifade etmeye zorlamak, öğrencilere eşit fırsat vermemek anlamına gelmektedir. Örneğin, dışa dönük bir kişilik yapısına sahip öğrencilerin, özellikle dil üretimi faaliyetlerinde, içe dönük olanlardan daha öne çıkacağı, bu sayede hem değerlendirme yapan öğretmenin gözünde akademik başarısının artacağı, hem de dil bilgisi adına önemli ölçüde ilerleme kaydetmesi olağandır.

Dewaele (2005) bireysel farklılıkların dil eğitimi alanında fazla ele alınmadığını öne sürmüştür. Araştırmalarda genellikle bireylerin değil, sınıftaki öğrencilerin bir bütün olarak ele alındığını bildirmiştir. Bu bakış açısı, öğrencileri tek bir ölçütle değerlendirmek, bireysel farklılıkları göz ardı etmektedir. Bireysel farklııklar, öğrencilerin öğrendikleri yabancı dildeki başarısını büyük ölçüde etkilemektedir.

\section{Psikodilbilimsel ve Beyindilbilimsel Modeller}

Son olarak, hedef dilin sınıf ortamında kullanılan tek dil olması ve anadilin tamamen kullanım dışı bırakılması dilin beyinde işlemlenmesini açıklayan psikodilbilimsel modeller açısından da değerlendirilmelidir. Alanyazında yapılan çalışmalar, birden fazla dil bilen bireylerin o dillere ait tüm bilgileri ortak bir depoda sakladığı görüşünü desteklemektedir (Dijkstra ve van Heuven, 2002; Marian, 


\section{Beyin Araştırmaları Işığında Yabancı Dil Sınıflarında Anadili Kullanımı}

Spivey ve Hirsch, 2003; Brysbaert ve Dijkstra, 2006; Dijkstra ve van Heuven, 2010; Spalek vd., 2014). Bu görüşe göre, dilin üretimi ve algısında bu depoda bulunan tüm dil özellikleri aktive olur. Paralel Aktivasyon adıyla bilinen bu durum gereği, dil işlemleme kullanımda olan dil öğelerinin kuvvetlendirilmesi, kullanılmayan dile ait öğelerin ise baskılanmasıyla gerçekleşmektedir. Kuvvetlendirme ve baskılama sürecinin sorunsuz ilerlemesi ilk olarak dikkat sistemi (Moreno ve Kutas, 2005), daha sonra da dillerin kullanım sıklığı ile yakından ilişkilidir (Duyck vd., 2008; Gollan vd., 2008; Lehtonen vd., 2012). Daha önce belirtildiği gibi, anadilin ediniminden sonra öğrenilen dilin üretimi ve algısı konuşucular üzerinde önemli bir bilişsel yük oluşturmaktadır (Hasegawa vd., 2002). Özellikle karmaşık dilbilgisi yapılarının işlemlenmesinde bu bilişsel yükün daha fazla olduğu görülmüştür (Suh, vd., 2007). Ayrıca, sınıf ortamında öğrenilen dilde yeterlilik düzeyi yüksek olmasına rağmen, bu dili işlemlemede, anadilinde bilinçaltında devam eden bir çeviri süreci olduğuna dair çalışmalar da vardır (Wu ve Thierry, 2012). Tüm bu bulgulara bakıldığında, dilin algısı ve üretiminde beyindeki anadili aktivasyonunu baskılamak bilişsel olarak imkansızdır. Yabancı dil sınıflarında, iletişimin sadece hedef dille sürdürülmesi gerektiği görüşünün deneysel çalışmalar tarafından desteklendiğini söylemek zordur. Bu sebeple, sınıftaki her türlü iletişimin hedef dille yapılması zorunluluğu, dil işlemleme prensiplerine aykırı bir yaklaşımdır.

Yabancı dil sınıflarında sadece hedef dilde iletişimin sağlanmasını vurgulayan görüşler, dil işlemlemede dilbilgisel ve anlamsal dil işlemleme arasında görülen farklılıkları da göz ardı etmiş görünmektedir. Öncelikle, beyinde dilin dilbilgisel ve anlamsal içeriğinin dil edinim/öğrenim yaşından, öğrenme ortamından ve kullanım sıklığından farklı şekillerde etkilendiği psikodilbilim (McDonald, 2006) ve beyindilbilimi (Guo, 2009) alanında yapılan çalışmalar tarafından ortaya çıkarılmıştır. Bu çalışmalar, anadilden sonra öğrenilen dilde dilbilgisel işlemlemenin, anadildekinden farklı olduğunu göstermektedir. Dilin sözdizimsel ve biçimbilimsel açıdan çözümlenmesinin edinim yaşı ile yakından ilişkili olduğunu gösteren çalışmaların sayısı bir hayli fazladır (Wartenburger vd., 2003; Paradis, 2004: 59; Clahsen ve Felser, 2006; Felser ve Clahsen, 2009; Saur vd., 2009; Mergen, 2010). Dildeki yeterlilik düzeyine bağlı olarak görece bir hız ve doğruluğa erişilmekle birlikte, anadili konuşucuları düzeyine ulaşıldığına ilişkin net bir veri elde edilmiş değildir (Paradis, 2004: 60). Aslında, alanyazında, dilin dilbilgisel öğelerinin işlemlenmesine ilişkin önemli bir fikir birliği olduğunu söylemek yanlış olmaz. Örneğin, Felser ve Clahsen (2009) alanyazında dilbilgisel işlemleme üzerine yapılan araştırmaları inceledikleri çalışmalarında, anadilinden sonra öğrenilen dilde biçimbilimsel ve sözdizimsel dil öğelerinin anadili konuşucularından farklı olduğuna dikkat çekmişlerdir. Yazarlar, sözü edilen farklılıkları dil öğrenen bireylerin yabancı dili işlemlemede daha yavaş olmalarıyla ilişkilendirmişlerdir. Benzer şekilde, Clahsen ve Felser (2006) anadilinden sonra öğrenilen dilde yapılan dilbilgisel işlemlemede, bilişsel kaynakların o dilin anadili konuşucuları kadar etkili kullanılamadığını 
bildirmişlerdir. Yüzeysel Yapı Varsayımı olarak bilinen bu görüşe göre, bireyler anadilden sonra öğrenilen dilde, anadildeki gibi dilbilgisel işlemleme mekanizmalarına sahip değildir. Bunu telafi etmek üzere, anlamsal, sözcüksel ve yüzeysel ipuçlarını değerlendirerek işlemleme yapmaktadırlar. Beyin sinyallerinin alındığı çalışmalar da bu fikri desteklemektedir (Weber ve Lavric, 2008). Sonradan öğrenilen dilde, dilbigisel işlemlemenin aksine, dilin anlamsal açıdan çözümlenmesi bireyler için önemli bir zorluk teşkil etmemekte, öğrenme yaşı gibi faktörlerden etkilenmemekte ve öğrenilen dildeki yeterlilik düzeyine bağı olarak anadili konuşucularına benzer bir hale gelebilmektedir. Örneğin, Weber-Fox ve Neville (1996) farklı yaşlarda ikinci dil öğrenen bireylerle yaptıkları kapsamlı çalışmada, ikinci dillerini 1-3, 4-6, 7-10, 11-13 yaş aralıklarında ve 16 yaşından sonra öğrenen 5 grup katılımcıdan, farklı zorluk derecelerinde dilbilgisel ve anlamsal olarak doğru ve yanlış cümlelerin hatalı olup olmadıklarını tespit etmelerini istemişlerdir. 1-3 yaş aralığında dil öğrenen bireylerin dilbilgisel işlemlemede hız ve doğruluk açısından ikinci dillerini 11-13 yaş aralığında ve 16 yaşından sonra öğrenen katılımcılara göre daha başarılı olduğu ortaya çıkmıştır. Yazarlar bu bulguları, farklı dil özelliklerinin dil öğrenme yaşından farklı şekillerde etkilendiği şeklinde yorumlamışlarıdır. Bu bulgular, dil öğrenim yaşı ile ilgili yapılan en kapsamlı ilk çalışma olması açısından önemlidir. Günümüze kadar yapılan çalışmalarda ise, bu çalışmada edinilen bulgulara zıt bir çalışma bulunmamaktadır.

Yabancı dil öğretiminde anadili kullanımına getirilen kısıtlamaların değerlendirilmesinde, sözcüklerin zihinsel yapılanmasının da göz önünde bulundurulması gerekmektedir. Bu, özellikle ilk bölümde değinilen duygu içerikli sözcüklerin kullanımı için önemlidir. Alanyazında yapılan çalışmalar, duygu sözcüklerine erişimin somut ve soyut sözcüklerden farklı olduğuna işaret etmektedir. Örneğin, Altarriba ve Bauer (2004) duygu sözcüklerinin somutluk, imgelenebilirlik ve bağlamsal erişim açısından, somut ve soyut sözcüklerden farklı bir yapıya sahip olduklarını ve bu sebeple farklı bir kategoride ele alınmaları gerektiğini bildirmişlerdir. Yabancı dil eğitiminde bunları aynı kategorideymiş gibi ele almak ve öğrencilerin bu sözcükleri diğerleri gibi algılamalarını ve kullanmalarını beklemek sakıncalı bir yaklaşımdır. Örneğin, bir okuma parçasında öğretilmesi hedeflenen sözcüklerin, ya da bir ders kitabının herhangi bir ünitesinde yer alan sözcük listelerinin belirlenmesinde bu farklılıklar ne kadar göz önünde bulundurulmaktadır? Bir dil sınıfında bu sözcüklerin iletişim aracı olarak kullanılması ya da test edilmesinde bu tür sözcüklerin herhangi bir sözcükmüş gibi ele alınması ne kadar doğru olacaktır? Duygu sözcükleriyle ilgili bir başka önemli nokta ise bu sözcüklerin zihinde somut ve soyut sözcüklerden farklı şekilde temsil edildiği, işlemlendiği ve hatırlanmalarıdır. Bu yönüyle duygu sözcükleri psikodilbilim ve beyindilbilim alanında yapılan birçok çalışmanın konusu olmuştur. Örneğin, olumlu sözcüklerin olumsuz ve nötr sözcüklere göre daha hızlı tanındığına ilişkin önemli veriler elde edilmiştir (Kuchinke vd., 2005; Kissler vd., 2009; 


\section{Beyin Araştırmaları Işığında Yabancı Dil Sınıflarında Anadili Kullanımı}

Kissler ve Koessler, 2011). Olumsuz sözcüklerin ise evrimsel bir miras olarak, beyindeki dikkat sistemini daha fazla meşgul ettiği ve işlemlenmesinin farklı stratejilerle gerçekleştiği bilinmektedir (Taylor, 1991), ancak yabancı dil öğretimde belirlenen hedeflerin bu noktalara ne ölçüde dikkat ettiği tartışmaya açıktır.

Dillerin zihinsel yapılanmasında önemi olan bir başka nokta da, sözcüklerin farklı kültürlerde farklı anlamlara karşılık gelmesidir. Bu farklııklar konusunda bir yönlendirme yapılmadığı takdirde, öğrencilerin bu yapıları tam olarak öğrenmeleri, dolayısıyla hedef dilde kullanmaları beklenemez. Bu görüşü destekleyen bir çalışmada, Pavlenko ve Driagina (2007) Rusça ve İngilizce'nin anadili konuşucularından izledikleri bir filmi anlatmalarını istemişler ve katılımcıların anlatımlarını karşılaştırmışlardır. iki grup arasında anlatıların uzunluğu, sözcük çeşitliliği, kullanılan dilbilgisi yapıları ve duygu içerikli durumları ve kişileri yorumlama şekilleri arasında farklılıklar olduğu görülmüştür. Bu bulgular, aynı olay, olgu ve durumların farklı kültürler tarafından, farklı şekillerde algılandığını ve ifade edildiğini göstermektedir. Bu farklılıkların, sınıf ortamında hedef dil kullanılarak anlatılması, öğrenciye bir katkı sağlamayacağı gibi, öğrencilerin de doğru bir şekilde kullanmalarına olanak tanımayacaktır. Bu çalışmadaki anadili konuşucuları arasındaki bu bulgular farklı bir kültürün dilini öğrenen öğrenciler için tasarlanan eğitim programlarında göz önünde bulundurulması gereken noktalardır. Sözü edilen bu farklılıklar, duygu ifade eden sözcükler için tekrar gözden geçirilmesi gereken bir durumdur. Pavlenko (2008), duygu sözcüklerinin zihinsel yapılanmasını ele aldığı çalışmasında duygu sözcüklerinin ikidilli bireylerde farklı şekillerde temsil edildiğini bildirmektedir. Buna göre, iki dil arasındaki kavramlar, tamamen (complete overlap) ya da kısmen (partial overlap) örtüşebildiği gibi bazı durumlarda tamamen farklı anlamlara (no overlap) karşılık gelebilirler. Bu kavramlar genellikle kültüre özel kavramlardır. Pavlenko en çok kısmen örtüşen kavramlar üzerinde durmaktadır. i̇ki dilde kısmen örtüşen sözcüklerin zaman içinde anlamsal açıdan değişim gösterebileceğine dikkat çeken Pavlenko, bu değişimi ancak ikinci dilin konuşulduğu ülkede yaşayan bir bireyin deneyimleyebileceğini ve bunun sonucunda zihinsel sözlükçenin tekrar yapılandırıldığını bildirmiştir.

\section{Sonuç}

Anadili dışında bir dil bilmenin zorunluluğunun tartışılmaz olduğu günümüzde, yabancı dil eğitimini daha etkin kılmak için birçok görüş ortaya atılmıştır. Bu görüşler, yabancı dil sınıflarında anadili kullanımına farklı şekillerde yaklaşmışlardır. Bunlar içerisinde, öğrenilen dile ilişkin dil girdisini azami bir seviyede olmasını hedefleyen görüşler en çok destek bulanlarıdır. Ancak, uygulamada anadilinin kullanımının adeta yok sayılmasının, hatta yasaklanmasının öğrencilerin hedef dildeki başarısı üzerinde önemli etkileri olduğu düşünülmektedir. Bu makalede, bu etkiler duygusal (afektif), bilişsel ve psikodilbilimsel/beyindilbilimsel çalışmalardan elde edilen veriler ışı̆̆ında gözden geçirilmiştir. Alanyazında yapılan çalışmalar değerlendirildiğinde, yabancı dil sınıflarında anadili 
kullanımının tamamen bırakılması, hem öğretilen dildeki sözcüklerin duygu yükünü tam olarak yansıtamayacağı, hem de öğretmen ve öğrenciler arasındaki iletişimi tam olarak destekleyemeyeceği düşüncesi imkansız görülmektedir. Bu yaklaşımın bilişsel olarak da, yabancı dil öğrenme sürecinin bireylere getirdiği bazı kısıtlamaları göz ardı ettiği düşünülmektedir. Son olarak, psikodilbilim verileri ışığında, anadilinin sınıf ortamında kullanılmaması, beyinde dil işlemleme prensiplerine aykırı bir görüş olarak karşımıza çıkmaktadır.

Sonuç olarak, yabancı dil sınıflarında yürütülen çalışmalarda eğitimcilerin, eğitim bilimcilerin ve dil eğitimi veren kurum yöneticilerinin bazı noktaları göz önünde bulundurmaları önerilmektedir. Illk olarak, beyin temelli öğrenme kavramının dil eğitimi müfredatının hazırlanmasında yer almaya başlamasıyla, öğretim planlarının hazırlanmasında bu makalede sözü edilen duygusal, bilişsel ve beyindilbilimsel bakış açılarının dikkate alınması gerekmektedir. Öğrenci-öğretmen iletişiminde, sınıf içindeki ve sınıf dışındaki paylaşımların (disiplini sağlama, motive etme, geribildirim verme vb.) anadilinde yapılmasının da öğrenme sürecine önemli katkısı olacağı düşünülmektedir. Hatırlanması gereken bir başka husus, öğrencilerin sınıf içi çalışmalarında ya da yazılı-sözlü sınavlarda yaptıkları dil bilgisi hataları, dil öğrenmeye karşı tutumları, davranış tarzları ile ilgili geribildirim verme, ödüllendirme, cesaretlendirme, uyarma, ya da onaylamama, öğrencilerin kişisel sorunlarıyla ilgilenme ve onlara destek verme süreçlerinde anadili kullanımının öğretmenin kararına bağı olması ve öğrencinin lehine olacak şekilde kullanılmasıdır. Soyut ve anlaşılması zor dil yapılarının (bağlaçlar, anadilde olmayan dilbilgisi yapıları vb.) sözcüklerin ve kültüre özel durumlara ilişkin açıklamaların anadilinde yapılması öğrencilerin bu yapıları daha hızlı öğrenmeleri ve doğru kullanmaları açısından önemlidir. Anadili kullanımının yabancı dildeki yeterlilik düzeyine göre belirlenmesi de bu süreçte belirleyici bir unsurdur. Özellikle başlangıç düzeyindeki bir öğrencilerin olduğu bir sınıfta, dil öğretmenine hedef dil kullanımı konusunda daha esnek davranabilmesine olanak tanımak dil öğrenme sürecine önemli ölçüde katkı sağlayacaktır.

\section{Kaynaklar}

Altarriba, J. ve Bauer, L. M. (2004). The distinctiveness of emotion concepts: A comparison between emotion, abstract and concrete words. American Journal of Psychology, 117 (3): 389-410.

Anooshian, L. ve Hertel, P. (1994). Emotionality in free recall: language specificity in bilingual memory. Cognition and Emotion, 8: 503-514.

Abutalebi, J. (2008). Neural aspects of second language representation and language control. Acta Psychologia, 128: 466-478.

Brysbaert, M. ve Dijkstra, V. H. (2006). Changing views on word recognition in bilinguals. (Çevrim-içi https://bibliougent.be/input/download?func=downloadFile \& recordOId=685459\&fileOld=685554.) Erişim Tarihi: 29.01.2013.

Caldwell-Harris, C.L. ve Ayçiçeği-Dinn, A. (2009). Emotion and lying in a non-native language. International Journal of Psychophysiology. 71 (3): 193-204. 
Clahsen, H. ve Felser, C. (2006). How native-like is non-native language processing ? Trends in Cognitive Sciences, 10 (12): 564-570.

Dewaele J. M. ve Furnhamb, A. (1999). Extraversion: The unloved variable in applied linguistic research, Language Learning, 49 (3): 509-544.

Dewaele J. M. ve Furnhamb, A. (2000). Personality and speech production: a pilot study of second language learners, Personality and Individual Differences, 28: 355-365.

Dewaele, J. M. (2004a). The emotional force of swear words and taboo words in the speech of multilinguals. Journal of Multilingualism and Multicultural Development, 25 (2-3): 204-222.

Dewaele, J. M. (2004b). Blistering barnacles! What languages do multilinguals swear in? Estudios de Sociolinguistica, 5 (1): 83 -105.

Dewaele, J. M. (2005). Investigating the psychological and emotional dimensions in instructed language learning: obstacles and possibilities. The Modern Language Journal, 89, 367-380.

Dewaele, J. M. (2008). The emotional weight of I love you in multilinguals' languages. Journal of Pragmatics, 40 (10): 1753-1780.

Dewaele, J. ve Pavlenko, A. (2002). Emotion vocabulary in interlanguage. Language Learning, 52 (2): $263-322$.

Dewaele, J. ve Ip, T., S. (2013).The link between foreign language classroom anxiety, second language tolerance of ambiguity and self-rated English proficiency among Chinese learners. Studies in Second Language Learning and Teaching, 3 (1): 47-66.

Dewaele, J. ve Nakano, S. (2013). Multilinguals' perceptions of feeling different when switching languages, Journal of Multilingual and Multicultural Development, 34 (2): 107-120.

Dijkstra, T. ve van Heuven, W. T. B. (2002). The architecture of the bilingual word recognition system: from identification to decision. Bilingualism: Brain and Cognition, 5 (3): 175 - 197.

Dörnyei, Z. (1994). Motivation and motivating in the foreign language classroom. The Modern Language Journal, 78: 273-283.

Duyck, W.,Vanderelst, D., Desmet, T. ve Hartsuiker, R. J. (2008). The frequency effect in second-language visual word recognition. Psychonomic Bulletin and Review, 15 (4): 850-855.

Ehrman, M. E., Leaver, B. L. ve Oxford, R. L. (2003). A brief overview of individual differences in second language learning, System, 31: 313-330.

Ekman, P. (1992). An argument for basic emotions. Cognition and Emotion, 6 (3-4): 169-200.

Ellis, R. (2005). Principles of instructed learning. System, 33: 209-224.

Felser, C. ve Clahsen, H. (2009). Grammatical processing of spoken language in child and adult language learner. Journal of Psycholinguistic Research, 38: 305-319.

Gollan, T. H., Montoya, R. İ, Cera, C. ve Sandoval, T. C. (2008). More use almost always a means a smaller frequency effect: Aging, bilingualism and the weaker links hypothesis, Journal of Memory and Language, 58(3): 787-814.

Guo, J., Guo T., Yan Y., Jiang N., ve Peng, D. (2009). ERP evidence for different strategies employed by native speakers and L2 learners in sentence processing. Journal of Neurolinguistics, 22: 123-134.

Harris, C. L. (2004). Bilingual speakers in the lab: psychophysiological measures of emotional reactivity. Journal of Multilingual and Multicultural Development, 25 (2): 223-247.

Harris, C. L., Ayçiçeği, A. ve Gleason, J. B. (2003). Taboo words and reprimands elicit greater autonomic reactivity in a first language than in a second language, Applied Psycholinguistics, 24: 561-579.

Hasegawa, M., Carpenter, P. A. ve Just, M. A. (2002). An fMRI study of bilingual sentence comprehension and workload, Neurolmage, 15: 647-660. 
Indefrey, P. (2006). A metaanalysis of hemodynamic studies on first and second language processing: Which suggested differences can we trust and what do they mean? Language Learning, 56: 279-304.

Kissler, J., Herbert, C., Winkler, I. ve Junghofer, M. (2009). Emotion and attention in visual word processing - an ERP study. Biological Psychology, 80 (1): 75-83.

Kissler, J. ve Koessler, S. (2011). Emotionally positive stimuli facilitate lexical decisions - an ERP study. Biological Psychology, 86 (3): 254-264.

Krashen, S. (1982). Principles and Practice in Second Language Acquisition. (Çevrim-içi http://www.sdkrashen.com/content/books/principles_and_practice.pdf), Erişim Tarihi: 11.03.2016).

Kuchinke, L., Jacobs, A. M., Grubich, G., Vo, M. L., Conrad, M. ve Herrmann, M. (2005). Incidental effects of emotional valence in single word processing: an fMRI study. Neurolmage, 28 (4): 1022-1032.

Kuhl, P. (2004).Early language acquisition: Cracking the speech code. Nature Reviews, 5: 831-843.

Kuhl, P. (2010). Brain mechanisms in early language acquisition. Neuron, 67: 713-727

Lehtonen, M.,Hulten, A., Rodriguez-Fornells, A, Cunillera,T., Tuomainen, J. ve Laine, M. (2012). Differences in Word recognition between early bilinguals and monolinguals: behavioral and ERP evidence. Neuropsychologia, 50 (7): 1362-1371.

Lewis, M. (2004) The emergence of human emotions. Lewis, M. ve Haviland-Jones, J (Ed), Handbook of Emotions, (ss. 265-280). New York: The Guilford Press.

Littlewood, W. Ve Yu, B. (2011). First language and the target language in the forign language classroom. Language Teacher, 44 (1): 64-77.

Lopez, Mariza G. Mendez ve Aguilar, A. P. (2013). Emotions as enhancers of foreign language learning motivation. Profile, 15 (1): 109-124.

Macaro, E. (2005). Codeswitching in the L2 classroom: A communication and learning strategy. E. Llurda (Ed.), Non-native language teachers. Perceptions, challenges and contributions to the profession (ss.63-84). New York: Springer.

Marian, V.,Spivey, M. ve Hirsch, J. (2003). Shared and separate systems in bilingual language processing: converging evidence from eye-tracking and brain imaging. Brain and Language, 86 (1): 70-82.

McDonald, J. (2006). Beyond the critical period Processing-based explanations for poor grammaticality judgement performance by late second language learners. Journal of Memory and Language, 55: 381401.

Mergen, F. (2010). Ikidilli bireylerin anadilinde ve ikinci dilde dilbilgisel ve anlambilimsel işlemlemelerinin nörodilbilimsel açıdan incelenmesi. İzmir: Dokuz Eylül Üniversitesi Sosyal Bilimler Enstitüsü, Yayınlanmamış Yüksek Lisans Tezi.

Moreno, E. M. ve Kutas, M. (2005). Processing semantic anomalies in two languages: an electrophysiological exploration in both languages of Spanish-English bilinguals. Cognitive Brain Research, 22 (2): 205-220.

Opitz, B. ve Degner, J. (2012). Emotionality is a second language: It's a matter of time. Neuropsychologia, 50 (8): 1961-1967.

Paradis, M. (2004). A Neurolinguistic Theory of Bilingualism, Hollanda: John Benjamins Publishing Company.

Pavlenko, A. (2004). "Stop doing that, la komu skalaza!": Language choice and emotions in parent-child communication. Journal of Multilingual and Multicultural Development, 25 (2-3): 179 - 203.

Pavlenko, A. ve Driagina, V. (2007). Russian emotion vocabulary in American learners' narratives. The Modern Language Journal, 91:213-234.

Perani, D. ve Abutalebi, J. (2005). The neural basis of first and second language processing. Current Opinion on Neurobiology, 15: 202-206. 
Sakai, K. L. (2005). Language acquisition and brain development. Science, 3: 815-819.

Saur, D., Baumgaertner, A., Moehring, A. Büchel, C., Bonnesen, M., Rose ve diğerleri (2009). Word order processing in the bilingual brain. Neuropsychologica, 47 (1) : 158 - 168.

Segalowitz, N.,Trofimovich, P., Gatbonton, E., ve Sokolovskaya, A. (2008). Feeling affect in a second language. The role of $w$ ord recognition automaticity. The Mental Lexicon, 3 (1): 47-71.

Suh, S., Yoon, H. W., Lee, S., Chung, J. Y., Cho, Z. H. ve Park, H. (2007). Effects of syntactic complexity in L1 and L2: An fMRI study of Korean-English bilinguals. Brain Research, 1136: 178-189.

Spalek, K., , Hoshino, N., Wu, Y. J., Damian, M. ve Thierry, G. (2014). Speaking two languages at once: Unconscious native word form access in second language production. Cognition, 133: 226-231.

Taylor, S. E. (1991). Asymmetrical effects of positive and negative events: The mobilization-minimization hypothesis. Psychological Bulletin, 110 (1): 67-85.

Ullman, M. T. (2001). The neural basis of lexicon and grammar in first and second language: the declarative/procedural model. Bilingualism: Language and Cognition,4 (2): 105-122.

Ullman, M. T. (2004). Contributions of memory circuits to language: the declarative / procedural model. Cognition, 92: 231-270.

Ullman, M. T. (2015). The declarative / procedural model: A neurobiologically motivated theory of first and second language. Vanpatten, B. ve Williams, J. (Ed), Theories in Second Language Acquisition, (ss. 135159. 2015) New York: Routledge. (Çevrim-içi:

https://books.google.com.tr/books?hl=tr\&|r=\&id=2Q8hBQAAQBAJ\&oi=fnd\&pg=PA135\&dq=ullman+declarative +procedural+model\&ots=jz_OHjQscM\&sig=Frva2dKXEY6YVprIRdnF5pa1eYk\&redir_esc=y\#v=onepage\&q =ullman\%20declarative\%20procedural\%20model\&f=false), Erişim Tarihi: 11.03.2016.

Van Heuven, W. J. B. ve Dijkstra, T. (2010). Language comprehension in the bilingual brain: fMRI and ERP support for psycholinguistic models. Brain Research Reviews, 64 (1): 104-122.

Wartenburger, I.,Heekeren, H. R., Abutalebi, J., Cappa,S., F., Villringer, A. ve Perani, D. (2003). Early Setting of grammatical processing in the bilingual brain, Neuron, 37:159-170.

Weber-Fox C. M. ve Neville, H. J. (1996). Maturational constraints on functional specialization for language processing: ERP and behavioral evidence in bilingual speakers. Journal of Cognitive Neuroscience, 8 (3): 231-256.

Weber, K. ve Lavric, A. (2008). Syntactic anomaly elicits a lexico-semantic (N400) ERP effect in the second language but not the first. Psychophysiology, 45: 920-925.

Wu, Y. J. ve Thierry, G. (2012). Unconscious translation during incidental foreign language processing. Neurolmage, 59: 3468-3473.

\section{Extended Abstract}

Infants have the potential to speak as many languages as they are exposed to in their surroundings when they are born. This capacity, however, shrinks during the first year and they acquire the language of the environment they are born into. This acquisition process, which proceeds astonishingly smoothly in childhood, turns out to be painstaking in adulthood. A great number of views have been suggested to simplify this process for those learning a second language in formal contexts. The success of prioritizing the use of the target language as a means of communication in class has captured a lot of attention in the field of foreign language teaching literature. The main idea behind this approach is to maximize the target language (L2) use with a view to fostering an enriched atmosphere in which learners can use the target language as a means of communication. The idea has received considerable support from teachers and scholars in the SLA world, but has been misinterpreted as implying the total abandonment of the mother tongue (L1). This view has achieved a long-lasting popularity since it first appeared, strongly supported by claims that the increased target language input would accelerate the learning process. The opposing arguments, however, are worth some attention in the light of neuroscientific evidence. This article will introduce how the results of brain research into foreign language teaching suggest a reconsideration of the role and the amount of $L 1$ in a language class. Experimental 
research has shown that affective, cognitive and linguistic factors all determine the extent of $L 2$ success in the SLA classroom.

To begin with, the influence of affective factors has been long overlooked by SLA scholars, and the few attempts to include them have been restricted to motivation, personality differences, establishing rapport and creating a positive learning atmosphere in a language class, ignoring the physiological, biological and neurological aspects of emotion phenomena. As revealed by brain research, perception and expression of emotions are monitored by the early maturing parts in the brain. As infants are exposed to linguistic stimuli in early years, the brain parts that mediate linguistic processes mature in parallel with the emotional system. Due to the simultaneous maturing of both systems, L1 is has strong emotional resonances for speakers, while for a late-learned L2, emotional resonance varies depending on the age, context, and the manner of acquisition. Deficiency in the learners' ability to perceive and express emotionality in L2 is considered to have some implications for their learning progress. First, they will underuse emotional language, thus, sounding more formal and detached. More importantly, conducting the whole lesson in L2 brings about the risk of demotivation, slowing progress and weakening rapport between teacher and the students.

Another line of research has shown the impossibility of the total abandonment of L1 due to the cognitive resources that $L 2$ learners depend on. To begin with, processing L2 brings a heavy cognitive workload, particularly in early stages of learning. Early maturing brain systems interact with the language system in the case of L1 acquisition, thus leading to an automatic processing of the native language. There is an increased variety of brain sites recruited for processing L2 compared to L1, as shown by brain imaging literature. This variety has been interpreted as the necessity to compensate the difficulties $L 2$ speakers have due to lack of automaticity in L2 processing. Another point to consider as regards cognitive resources in L2 processing is the use of implicit (procedural) and explicit (declarative) memory. The former includes the knowledge acquired unconsciously, in the process of performing a task. Also, we depend more on the implicit memory in infancy, while the explicit memory, which stores declarative knowledge, takes control as we grow older. As suggested by Declarative / Procedural Model of language processing, these two systems process different language forms, i.e. the former processes grammar while the latter stores lexical knowledge. One thing to consider in L2 learning context is that, regardless of the amount of $L 2$ input, it is difficult for learners to process grammar as native speakers do. Another point is that, as shown by research, explicit knowledge from formal teaching cannot transform into implicit knowledge simply through repetition over time. One final aspect of the cognitive limitations of an L2-only approach in the classroom is that learners vary considerably in their personalities. Interestingly, there is some evidence that personality traits have some effect on memory capacity. For example, extroverts outperform introverts in short term memory skills, while the reverse is true for long-term memory skills. This aspect of memory is important in that learners may differ in their efficiency in using the target language according to their personality type.

Finally, evidence from psycholinguistic research should be taken into consideration in curriculum design for classroom teaching based on target-language-only view. Psycholinguistic literature abounds with support for the parallel activation of two languages in perception and production. Bilingual language processing functions by promoting facilitation or inhibition of each language depending on the context. This process is monitored by attentional resources and the frequency of use of the languages. Since L2 processing is less automatic as compared to L1, more attention is required, thus leading to a slowing down in language production and perception. Apart from attention-based requirements in language selection, there seems to be the added difficulty of processing L2 grammar, which requires different strategies from L1 processing. As predicted by the Shallow Structure Hypothesis, L2 learners underuse grammatical cues in language processing as they lack the strategies used by L1 speakers. To compensate, they resort to the lexical and pragmatic aspects of language to extract meaning. Another point to consider is the difference between the representations of $\mathrm{L} 1$ and L2 words in memory. There may be total, only partial or even no overlap at all between lexicons. If this is the case, $\mathrm{L} 2$ learners may struggle to express themselves if restricted to the target language.

In conclusion, despite all the interest and support it has received over the years, the L2-only approach to language teaching should be reconsidered in the light of evidence from the affective, cognitive and psycholinguistic literature. 